\title{
MicroRNA-454 may function as an oncogene via targeting AKT in triple negative breast cancer
}

\author{
Qun Li, Jia Liu, Xianying Meng, Renzhu Pang and Jie Li
}

\begin{abstract}
Background: Altered microRNAs expression mediates tumor development and progression in many type cancers including triple negative breast cancer (TNBC). Here we detected the effect of miR-454 on cell proliferation, migration and invasion of triple negative breast cancer cells.

Results: miR-454 promoted the proliferation of TNBC, and enhanced migration and invasion in TNBC cells. Meanwhile, miR-454 improved the survival of TNBC cells after ironizing radiation. miR-454 inhibited radiation-induced apoptosis in TNBC cells by regulation of caspase 3/7 and Bcl-2 expression. Furthermore, PTEN and pAKT levels in TNBC cells were changed after overexpression of miR-454.
\end{abstract}

Conclusions: miR-454 played an essential role in tumor development and progression in TNBC, and might be used as a potential biomarker to predict radiotherapy response and prognosis in TNBC.

Keywords: miR-454, Triple negative breast cancer, Apoptosis, AKT

\section{Background}

Breast cancer remained the most commonly diagnosed cancer in women and the second leading cause of cancer death among women [1]. In the past decade, early detection and screening and improvement in medical care and treatments decreased dramatically the mortality of patient with breast cancer $[2,3]$.

Triple-negative breast cancer (TNBC) is a subtype of breast cancer characterized as negative for estrogen receptors, progesterone receptors, and HER2 [4]. Studies have demonstrated that TNBC is an aggressive disease with unique molecular profile [5]. Brain and lungs are the most common metastasis sites of TNBC [6]. There are no targeted therapies for TNBC. Therefore, it is important to discovery of new molecular targets to treat patients with TNBC $[7,8]$.

It is well known that microRNAs (miRNAs) play critical roles in regulation of gene expression [9]. Studies have demonstrated that miRNAs can behave as both

\footnotetext{
*Correspondence: jie.li6@aol.com
}

The First Hospital, Jilin University, Changchun, Jilin, China oncogenes and tumor suppressor genes [10]. MiRNAs regulate many biological processes, such as cell proliferation, apoptosis and cell cycle. Several studies have shown that miR-10b improves cell migration and invasion by targeting HOXD10 [11, 12]. Huang et al. has reported that miR-21 is associated with breast cancer cell invasion and regulated epithelial-to-mesenchymal transition (EMT) [13]. Han et al. [14] has shown that miR-21 regulates breast cancer stem cell-like cells.

Zhang et al. has reported that miR-155 improves breast cancer cell proliferation by regulation of p53 [15]. miR$125 \mathrm{~b}$ is downregulated in breast cancer and correlates with metastasis and HER2 expression [16]. Recent studies indicate that miRNAs are associated with prognosis in breast cancer [17] while miR-454 plays critical roles in tumor development in many organs [18, 19]. Zhu et al. found that miR-454 promoted proliferation of non-small cell lung cancer cells by targeting PTEN [20]. The oncogene role of miR-454 is also found in uveal melanoma [18]. Yu et al. reported that miR-454 enhanced hepatocellular carcinoma cell proliferation, invasion and epithelial mesenchymal transition [21]. Liu et al. [19] and Liang 
et al. [22] showed that miR-454 regulated cell proliferation in colon cancer by different signaling pathways.

In this study, we examined the function of miR-454 on cell proliferation with or without radiation, invasion and migration using triple-negative breast cancer cell lines.

\section{Methods}

\section{Cell lines and cell culture}

Two human triple-negative breast cancer cell lines, MDA-MB-231 and MDA-MB-468 (ATCC, USA), were used in all experiments in our study in order to ensure all data are not cell-line restricted. These tumor cells were cultured in Dulbecco's modified Eagle's medium (DMEM) (Invitrogen, USA) supplemented with $100 \mu \mathrm{g} \mathrm{ml}^{-1}$ streptomycin, $100 \mathrm{U} \mathrm{ml}^{-1}$ penicillin and $10 \%$ fetal bovine serum (Invitrogen, USA) at $37{ }^{\circ} \mathrm{C}$ in a humidified incubator with $5 \% \mathrm{CO}_{2}$. When all cells reach to $80 \%$ confluence, they were harvested and used in our experiments.

\section{Cell transfection and miRNA quantification}

Lipofectamine 2000 (Invitrogen, USA) was used to transfer miR-454 mimics or anti-miR-454 inhibitor (Invitrogen, USA) into TNBC cells. A random sequence miRNA mimic molecule was used as a negative control (mirVana ${ }^{\mathrm{TM}}$ miRNA mimic, Ambion, USA). Then, miR454 expression level was examined by real time PCR after transfection. The total RNA was extracted from the transfected TNBC cells; TaqMan microRNA reverse transcription kit (ThermoFisher, USA) was used to synthesize cDNA according the manufacturer's instructions. GAPDH was used as the endogenous reference gene.

\section{Cell proliferation assay}

WST-1 assay (Roche, USA) was performed to analyze the function of miR-454 on TNBC cell proliferation. Briefly, the transfected TNBC cells were seeded into 96-well plates at the density of $2 \times 10^{4}$ cells well $^{-1}$. The cells were cultured overnight at $37{ }^{\circ} \mathrm{C}$ in a humidified incubator with $5 \% \mathrm{CO}_{2}$. Then, the TNBC cells were exposed to different doses of ionizing radiation. Then WST-1 reagent was added to each well and incubated for $1 \mathrm{~h}$ at $37^{\circ} \mathrm{C}$ every $24 \mathrm{~h}$. Afterwards, the absorbance was measured at $490 \mathrm{~nm}$. All experiments were performed in triplicates.

\section{Migration and invasion assays}

The Promega migration and invasion assays were performed to evaluate migration and invasion of TNBC cell following the manufacturer's instructions (Promega Corporation, USA). Briefly, transfected TNBC cells were placed on the upper transwell chamber either present or absent matrigel in DMEM. DMEM supplemented with $5 \%$ FBS was added to the lower chamber. The cells were cultured at $37{ }^{\circ} \mathrm{C}$ for $18 \mathrm{~h}$. Then Diff-Quik stain (Invitrogen, USA) was performed after the non-invaded cells were removed by cotton swabs. The migration and invasion was calculated and showed as a ratio of invaded cells over cells normalized on second day of growth curve.

\section{Western blot assay}

The TNBC cells were harvested and gently washed with cold phosphate buffered saline. The cells were lysed by adding ice-cold lysis buffer $(50 \mathrm{mM}$ Tris- $\mathrm{HCl}, \mathrm{pH} 7.5$, $0.1 \%$ SDS, $150 \mathrm{mM} \mathrm{NaCl}, 0.5 \%$ deoxycholate, $1 \% \mathrm{NP}-40$, and $1 \times$ protease inhibitors). The mixture was boiled at $100{ }^{\circ} \mathrm{C}$ for $5 \mathrm{~min}$. The same amount of protein lysates were loaded to the SDS-PAGE gel and transferred to PVDF membranes (Sigma, USA). The PVDF membranes were incubated in blocking buffer at room temperature for $1 \mathrm{~h}$. Primary antibodies (Bcl-2, Bax, AKT and pAKT; Cell Signaling Technology, USA) were added in TBS-T buffer and incubated at $4{ }^{\circ} \mathrm{C}$ overnight, followed by secondary antibody incubation at room temperature for $1 \mathrm{~h}$. The signals were examined with the EasySeeWeatern Blot Kit (Transgen, Shanghai).

\section{Apoptosis activity assay}

To examine the apoptosis activity of TNBC cells with altered miR-454 expression, the TNBC cells were grown in 24-well plates at density of $1 \times 10^{5}$ well $^{-1}$. Then the TNBC cells were exposed to different doses of ionizing radiation. The TNBC cells were continued to culture for $24 \mathrm{~h}$, the caspase-Glo3/7 assay kit (Promega, Madison, USA) was used to examine apoptosis activity by measure the caspase $3 / 7$ activity following the manufacturer's protocol. Briefly, caspase-Glo reagent was added to the TNBC cells, and incubated at room temperature in a dark place with gentle shaking for $8 \mathrm{~h}$. The luminescence value was measured using $1-\mathrm{min}$ lag time and $0.5 \mathrm{~s}$ well ${ }^{-1}$ read time. All experiments were carried out in triplicates.

\section{Statistical analysis}

SPSS software (version 11.0, IBM, USA) was used for statistical analyses using Student's $t$ test. Differences are considered statistically significant if $p<0.05$. 


\section{Results}

miR-454 increased the proliferation of TNBC cells and improved the survival at ionizing radiation

To examine the function of miR-454 on proliferation of TNBC cells, miR-454 was transfected to MDA-MB-231 and MDA-MB-468 TNBC cells with Lipofectamine 2000. WST-1 assay was performed to examine the proliferation. As shown in Figs. 1a and 2a, the miR-454 expression level was significantly increased in both MDA-MB-231 and MDA-MB-468 cells after overexpression of miR-454 mimic, and the miR-454 expression level was inhibited after transfection of anti-miR-454 inhibitor. miR-454 promoted the proliferation of MDA-MB-231 (Fig. 1b) and MDA-MB-468 cells (Fig. 2b) $(p<0.05)$. When the miR454 level was inhibited by anti-miR-454 inhibitor, the proliferation was decreased in MDA-MB-231 (Fig. 1c) and MDA-MB-468 cells (Fig. 2c) $(p<0.05)$. When the TNBC cells were exposed to ionizing radiation, miR-454 improved the survival of MDA-MB-231 (Fig. 1d-f) and MDA-MB-468 cells (Fig. $2 \mathrm{~d}-\mathrm{f})(p<0.05)$ at dose dependent manner.

\section{miR-454 decreased radiation-induced apoptosis in TNBC cells}

To determine the function of miR-454 on radiationinduced apoptosis in TNBC cells, the caspase-Glo 3/7 assay kit was used by measuring caspase $3 / 7$ activity, and apoptotic related protein was examined by western blot. As shown in Fig. 3, miR-454 inhibited the caspase $3 / 7$ activity in both MDA-MB-231 (Fig. 3a) and MDA-MB-468 (Fig. 3b) cells at dose dependent manner. The expression of BAX and Bcl-2 was altered in MDAMB-231 (Fig. 4c, d) and MDA-MB-468 (Fig. 4e, f) after upregulation of miR-454.

\section{miR-454 improved migration and invasion of TNBC cells}

The migration and matrigel invasion assays were used to examine the effect of miR-454 on migration and invasion of TNBC cells using BD transwell. As shown in Fig. 4, the migration and invasion of MDA-MB-231 (Fig. 4a-d) and MDA-MB-468 (Fig. 5a-d) were significantly increased after overexpression of miR-454. In contrast, downregulation of miR-454 significantly decreased the migration and invasion of MDA-MB-231 (Fig. 4e-h) and MDAMB-468 cells (Fig. 5e-h) $(p<0.05)$.

miR-454 inhibited PTEN and activated pAKT in TNBC cells The expression of $\mathrm{pAKT}$, total AKT, and PTEN was detected in both MDA-MB-231 and MDA-MB-468 cells after miR-454 overexpression. We found that miR-454 decreased the PTEN expression level and increased the expression of pAKT in both MDA-MB-231 (Fig. 6a, b) and MDA-MB-468 (Fig. 6c, d) cells.

\section{Discussion}

Recent studies have shown that miR-454 is highly expressed in tissue from patients with TNBC [23]. These findings indicate that miR-454 expression level might be positively correlated with worse clinical outcome. Therefore, miR-454 might act as a potential predictor of prognosis in TNBC. Recently, a tissue microarray study showed that miR-454 is associated with poor prognosis in patients with TNBC [23]. In our study, we found that miR-454 improved the proliferation of TNBC cells. Radiotherapy is one of highly effective adjuvant therapies in many types of cancer including breast cancer after surgery [24]. TNBC is a complex disease with features such as rapid growth and local recurrence. It has been reported that radiotherapy can decrease the locoregional recurrence in patients at early stage after surgery [25]. In the present study, we showed that miR-454 improved the survival of TNBC cells after ionizing radiation. Meanwhile, miR-454 inhibited the radiation-induced apoptosis of TNBC cells. Moreover, we showed that overexpression of miR-454 increased migration and invasion in TNBC cells. However, downregulation of miR-454 inhibited the migration and invasion in TNBC cells. It has been demonstrated that TNBC is more likely to recur and has poor prognosis [26]. Metastasis is one of important features for the recurrence of TNBC. Therefore, our study showed that miR-454 play critical roles in TNBC progression.

The PI3K/AKT pathway involves many biological processes and regulates the downstream responses including cell proliferation, apoptosis and cell cycle. It has been reported that PI3K/AKT is activated in TNBC due to PTEN mutation [27]. PTEN, known as the second most frequently mutated tumor suppressor gene in human cancer, plays important roles in proliferation, apoptosis and cell cycle in many type tumor cells. Recent studies have demonstrated that PI3K/AKT pathway is the key pathway by which PTEN displays antioncogenic functions [28]. Our results showed that PTEN expression level was downregulated, and pAKT expression level was increased in TNBC cells after overexpression of miR-454. These results indicated miR-454 mediated proliferation of TNBC cells by targeting PI3K/AKT signaling pathway. Further studies are needed to demonstrate the molecular mechanism. 


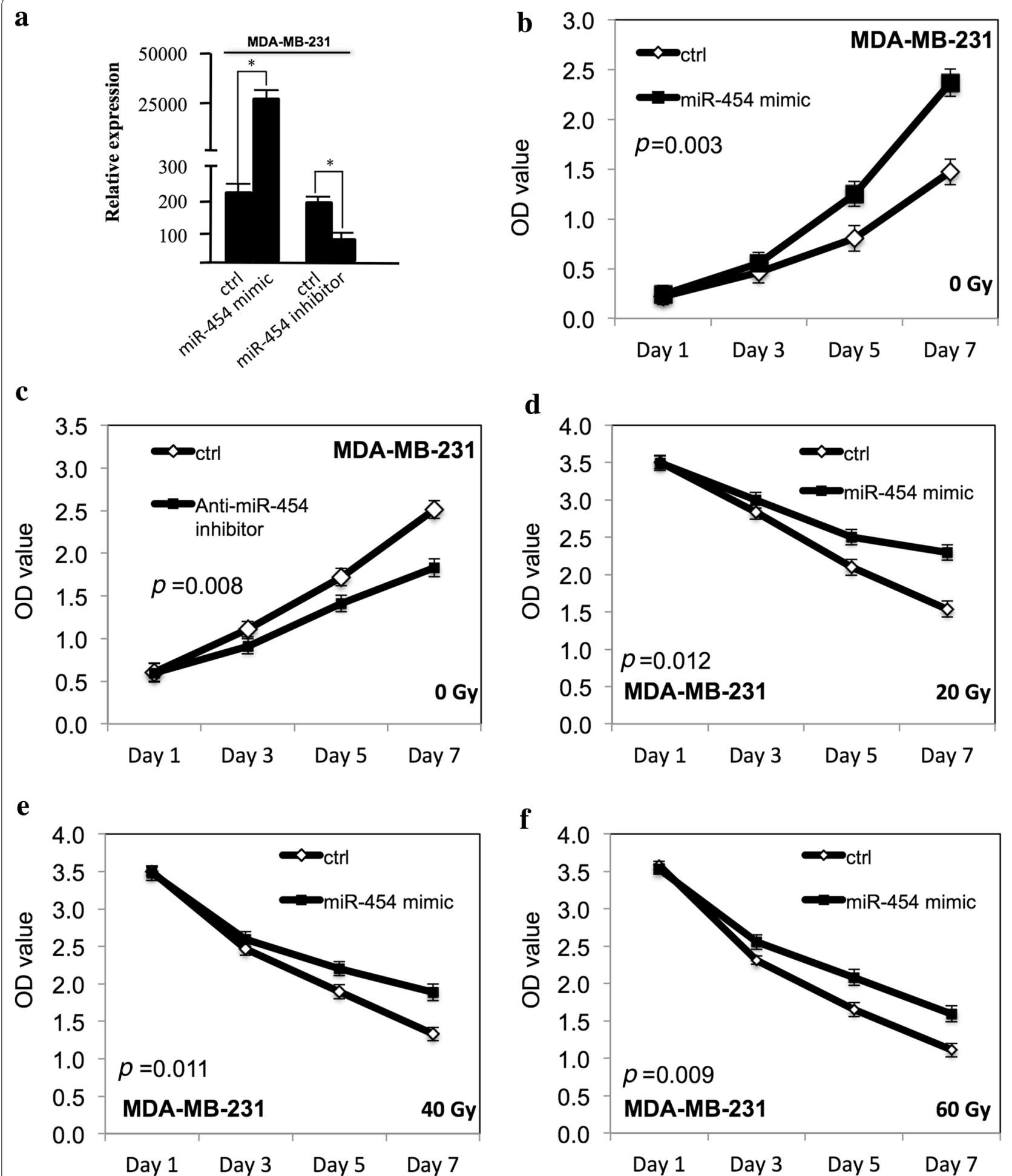

Fig. 1 miR-454 increased the proliferation of MDA-MB-231 cells and improved the survival at ionizing radiation. a The miR-454 expression level was determined by qRT-PCR in MDA-MB-231 cells transfected with either miR-454 mimic or anti-miR-454 inhibitor. b The proliferation of MDA-MB-231 cells after transfection of miR-454 mimic. c The proliferation of MDA-MB-231 cells after transfection with anti-miR-454 inhibitor. d The proliferation of MDA-MB-231 cells after miR-454 overexpression at $20 \mathrm{~Gy}$. e The proliferation of MDA-MB-231 cells after miR-454 overexpression at $40 \mathrm{~Gy}$. f The proliferation of MDA-MB-231 cells after miR-454 overexpression at $60 \mathrm{~Gy}$. All experiments were performed in triplicate 
a

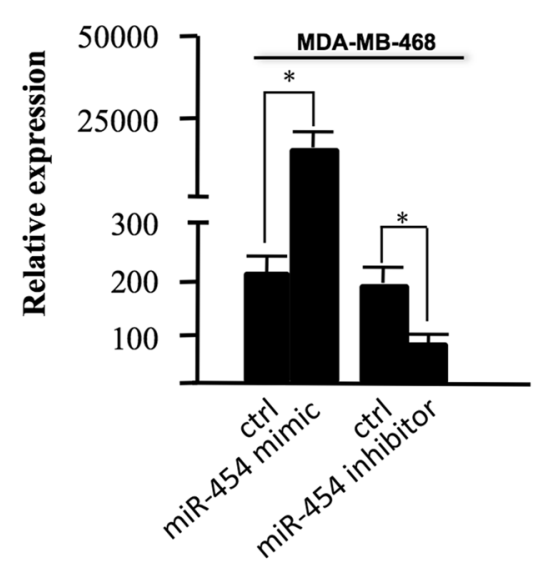

c

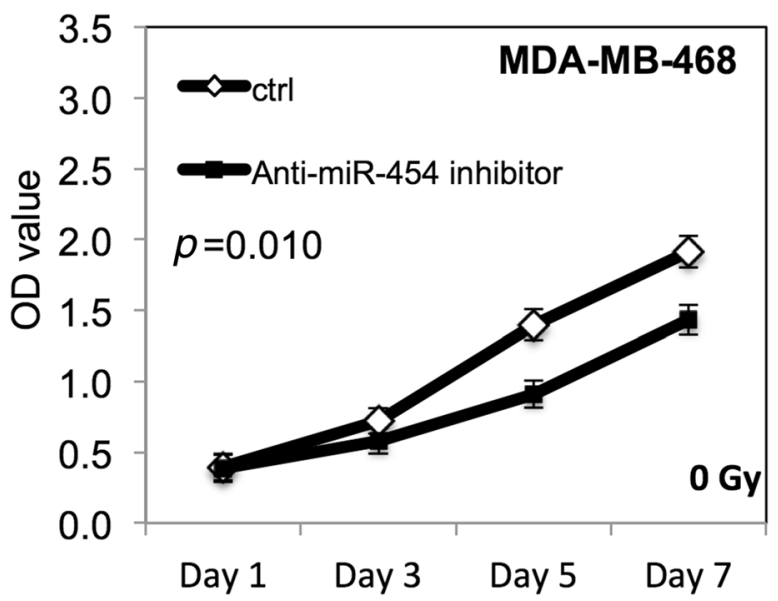

e

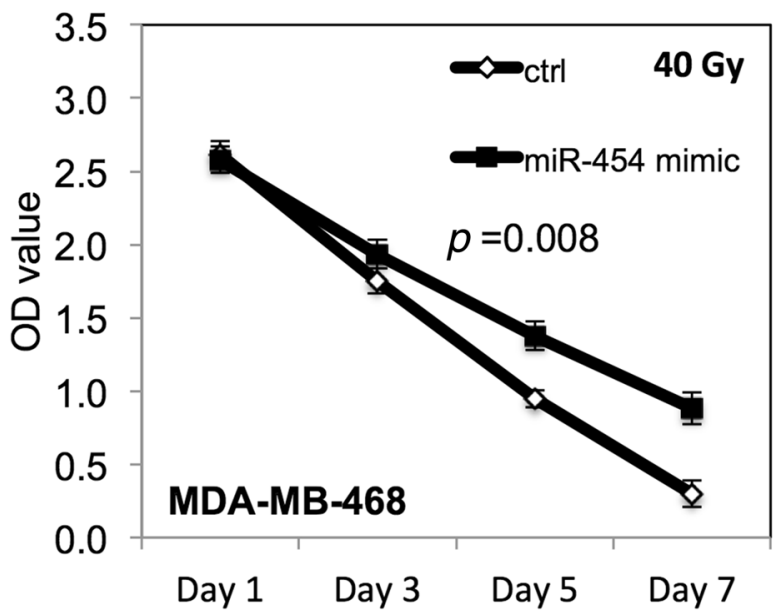

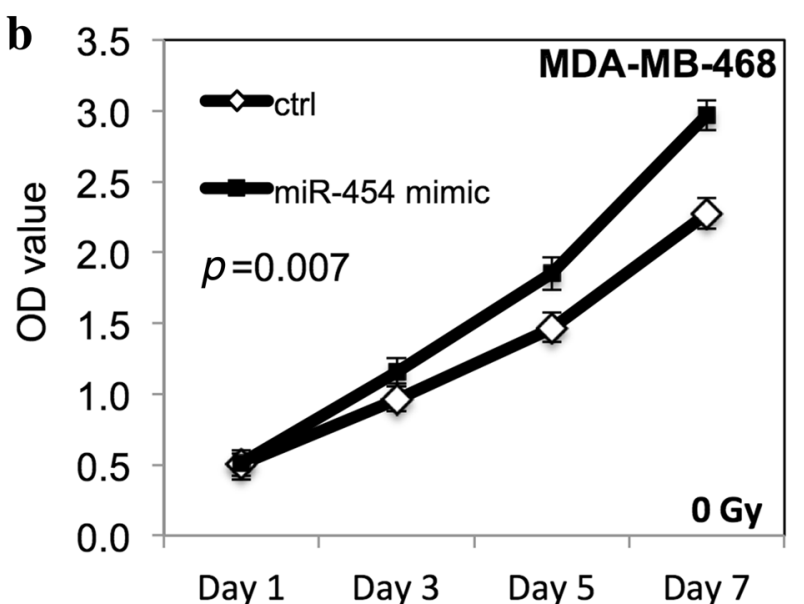

d

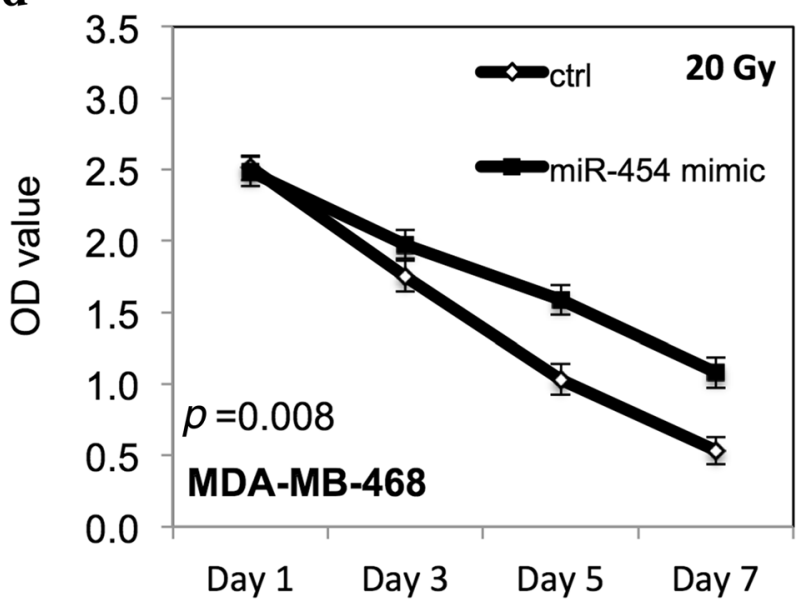

f

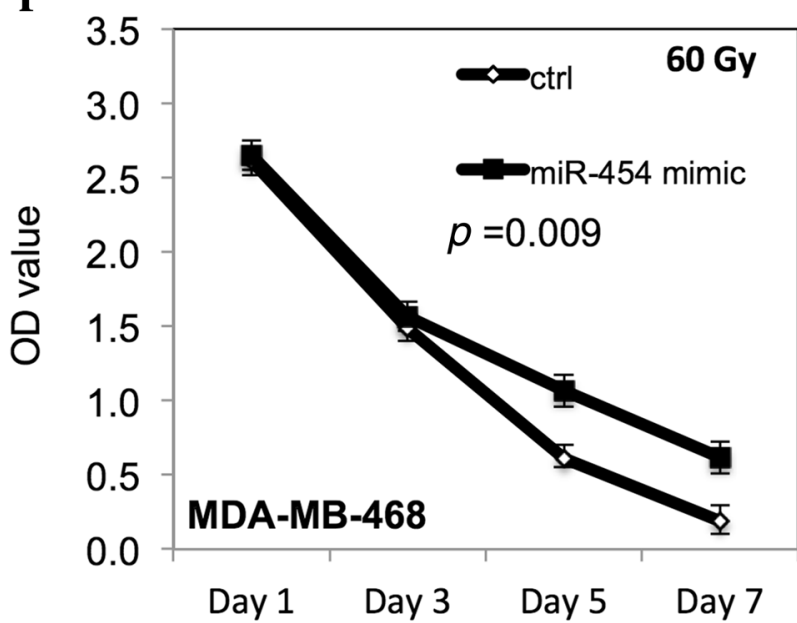

Fig. 2 miR-454 increased the proliferation of MDA-MB-468 cells and improved the survival at ionizing radiation. a The miR-454 expression level was determined by qRT-PCR in MDA-MB-468 cells transfected with either miR-454 mimic or anti-miR-454 inhibitor. b The proliferation of MDA-MB-468 cells after transfection of miR-454 mimic. c The proliferation of MDA-MB-468 cells after transfection with anti-miR-454 inhibitor. d The proliferation of MDA-MB-468 cells after miR-454 overexpression at 20 Gy. e The proliferation of MDA-MB-468 cells after miR-454 overexpression at 40 Gy. fThe proliferation of MDA-MB-468 cells after miR-454 overexpression at $60 \mathrm{~Gy}$. All experiments were performed in triplicate 

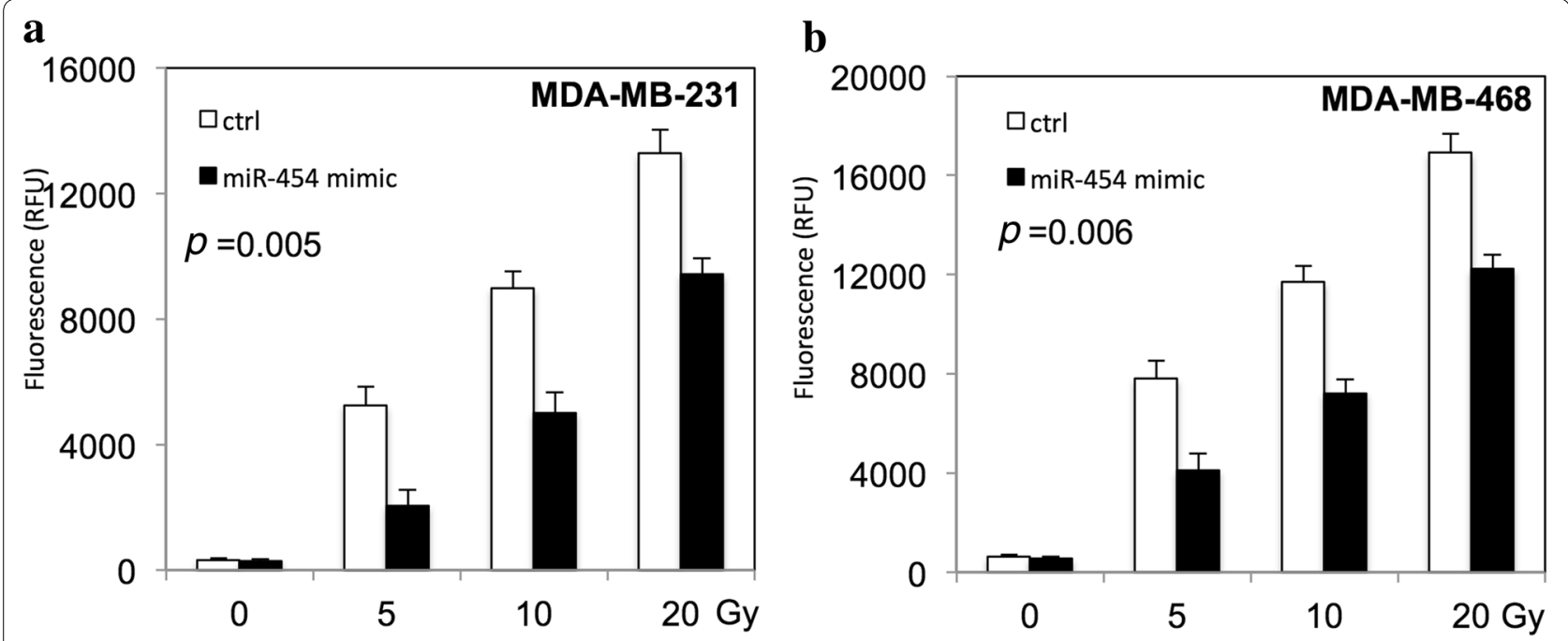

C

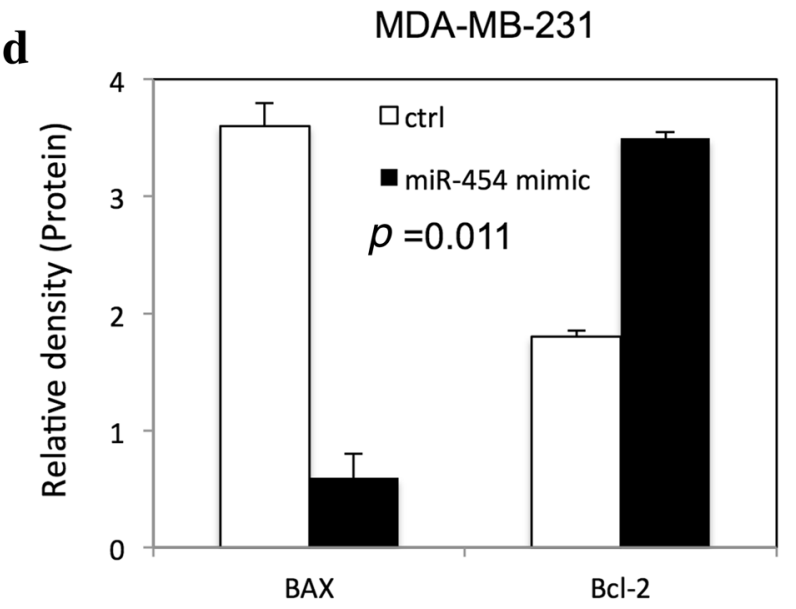

$\mathbf{e}$

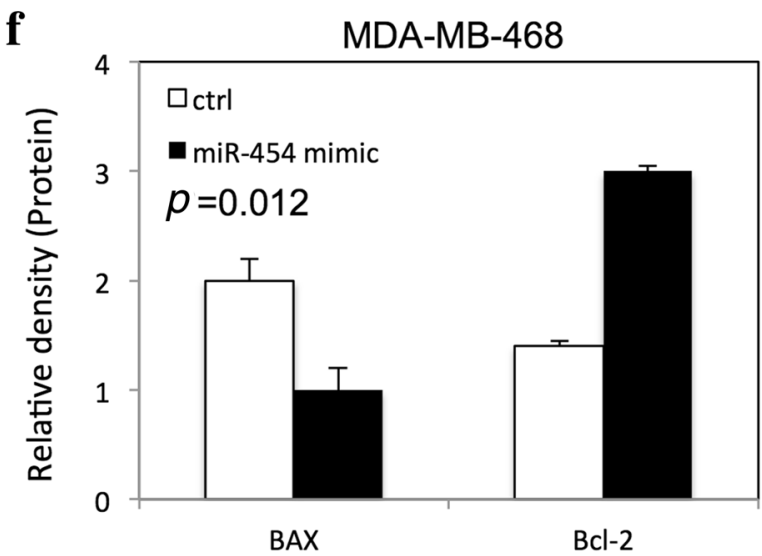

Fig. 3 miR-454 inhibits radiation-induced apoptosis in TNBC cells. a The caspase 3/7 activity of MDA-MB-231 cells transfected with miR-454 mimic after different doses of ionizing radiation. $\mathbf{b}$ The caspase 3/7 activity in MDA-MB-468 cells transfected with miR-454 mimic after different doses of ionizing radiation. $\mathbf{c}$, $\mathbf{d}$ The apoptotic proteins and RNA levels in MDA-MB-231 cells after transfection of miR-454 mimic. e, f The apoptotic proteins and RNA levels in MDA-MB-468 cells after transfection of miR-454 mimic. All experiments were performed in triplicate 


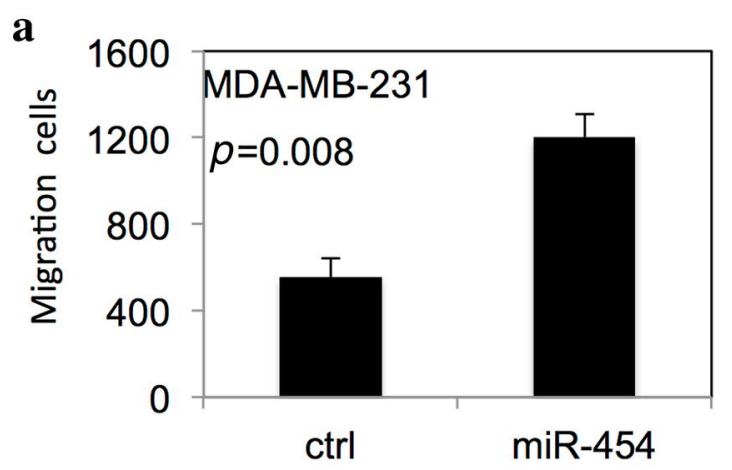

c

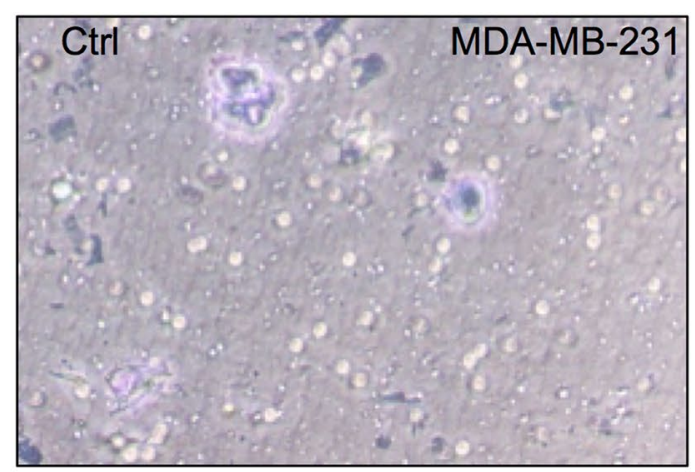

e

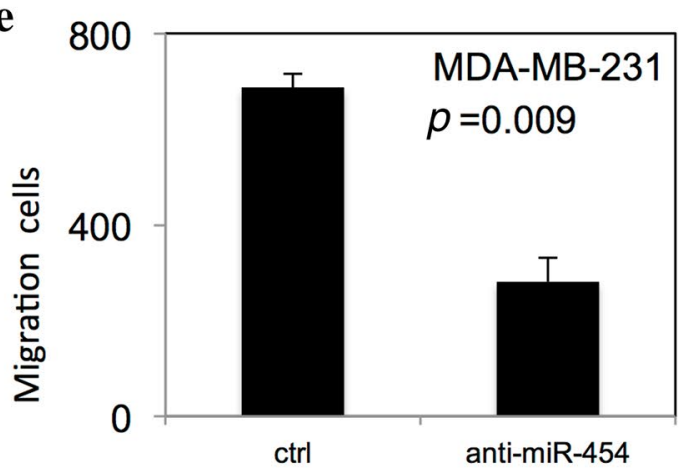

g

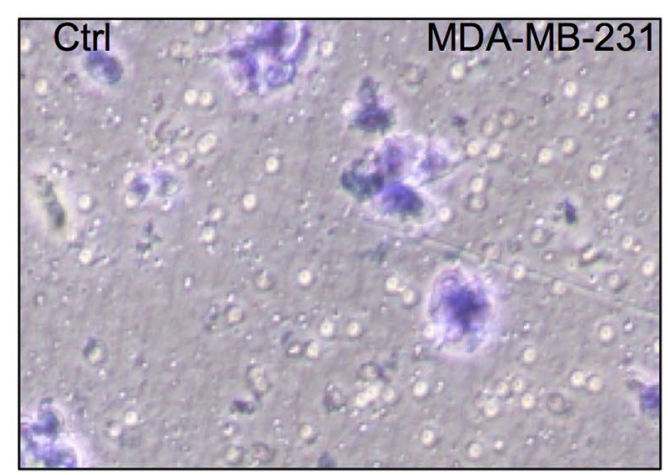

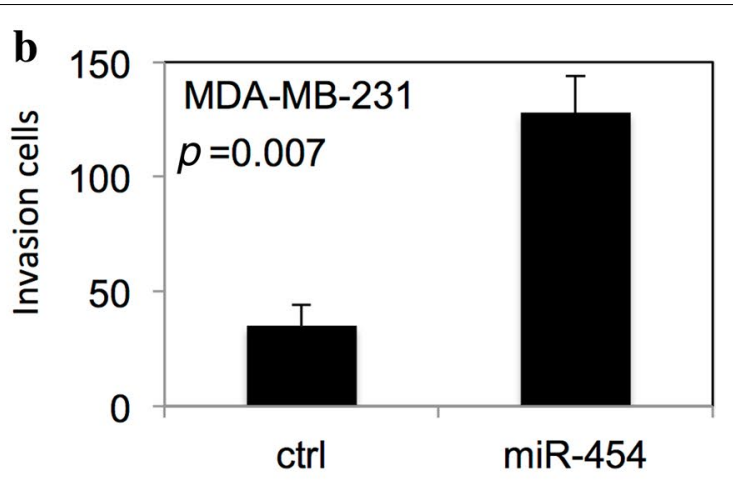

d

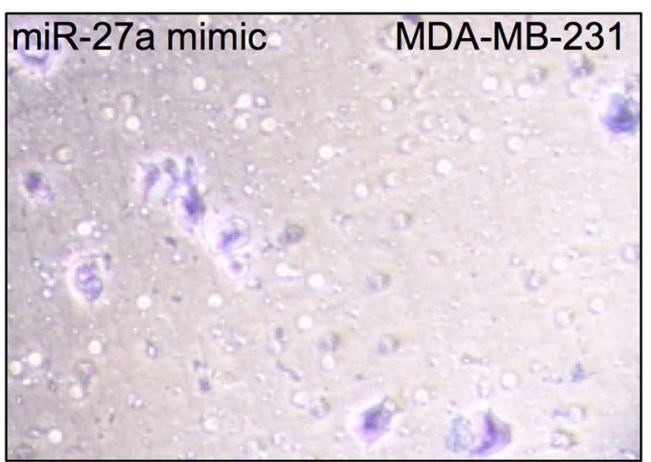

f

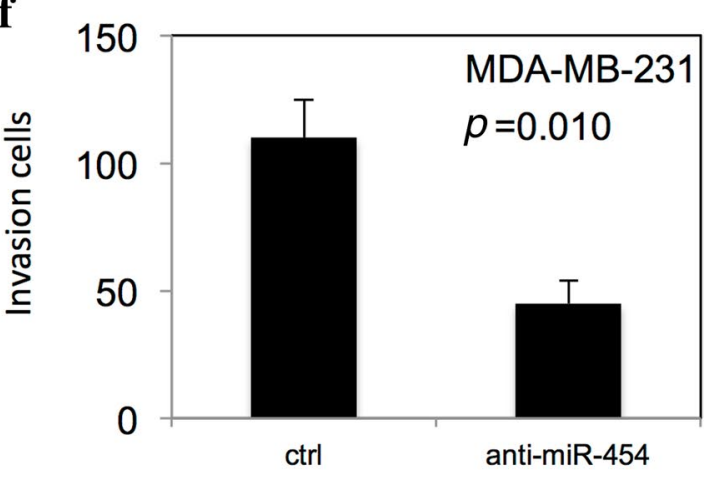

$\mathbf{h}$

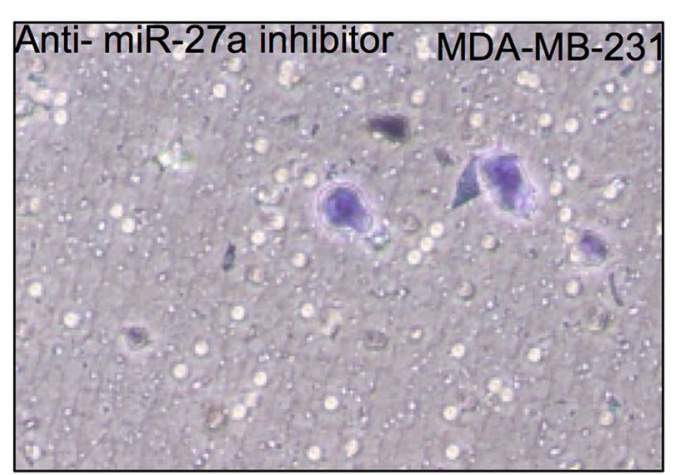

Fig. 4 miR-454 improved migration and invasion of TNBC cells. miR-454 improved migration and invasion of MDA-MB-231 cells (a-d). The migration and invasion of MDA-MB-231 cells were decreased after downregulation of miR-454 (e-h). The migration and invasion of MDA-MB-468 cells were decreased after downregulation of miR-454 (e-h). All experiments were performed in triplicate 

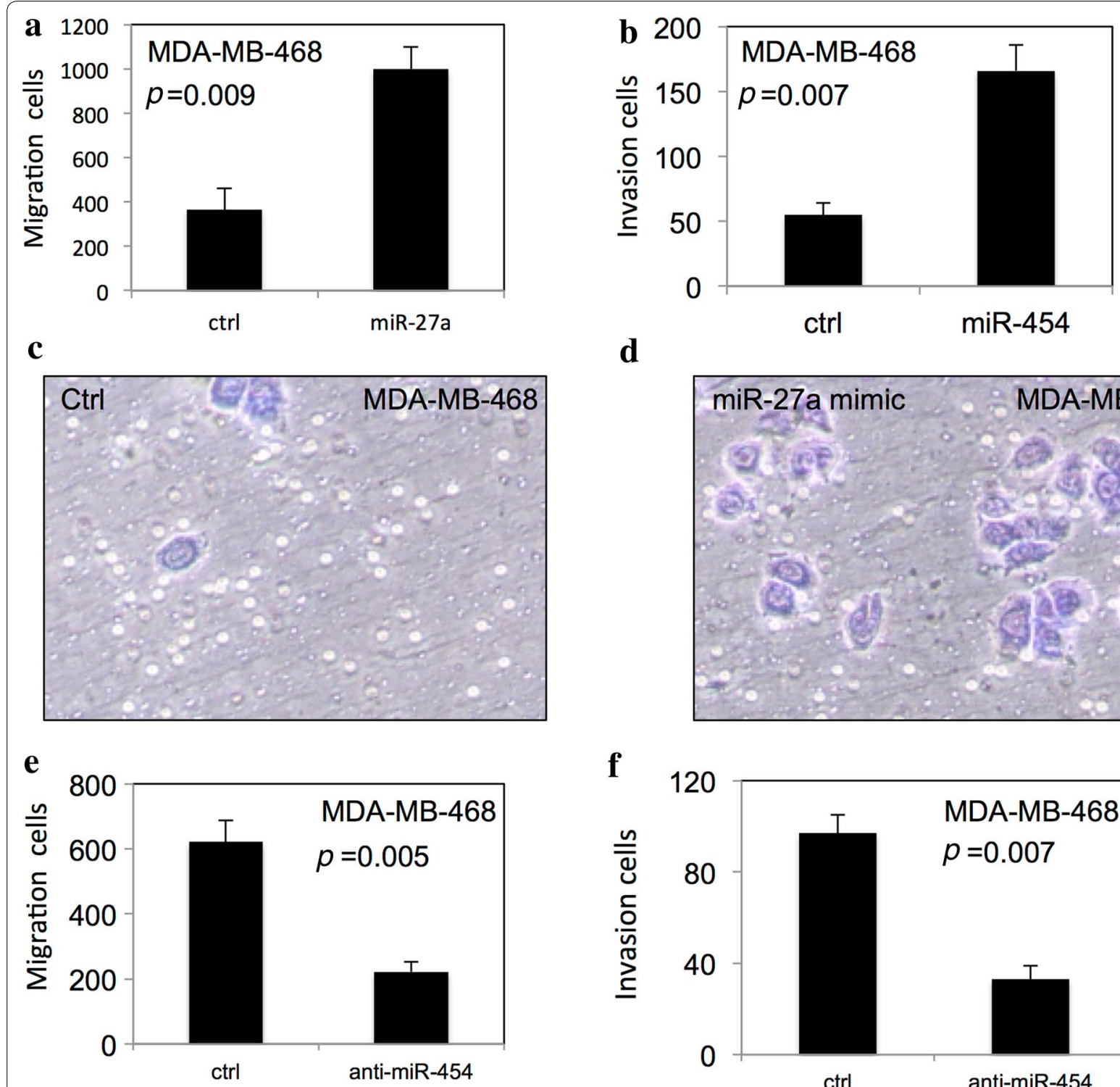

g
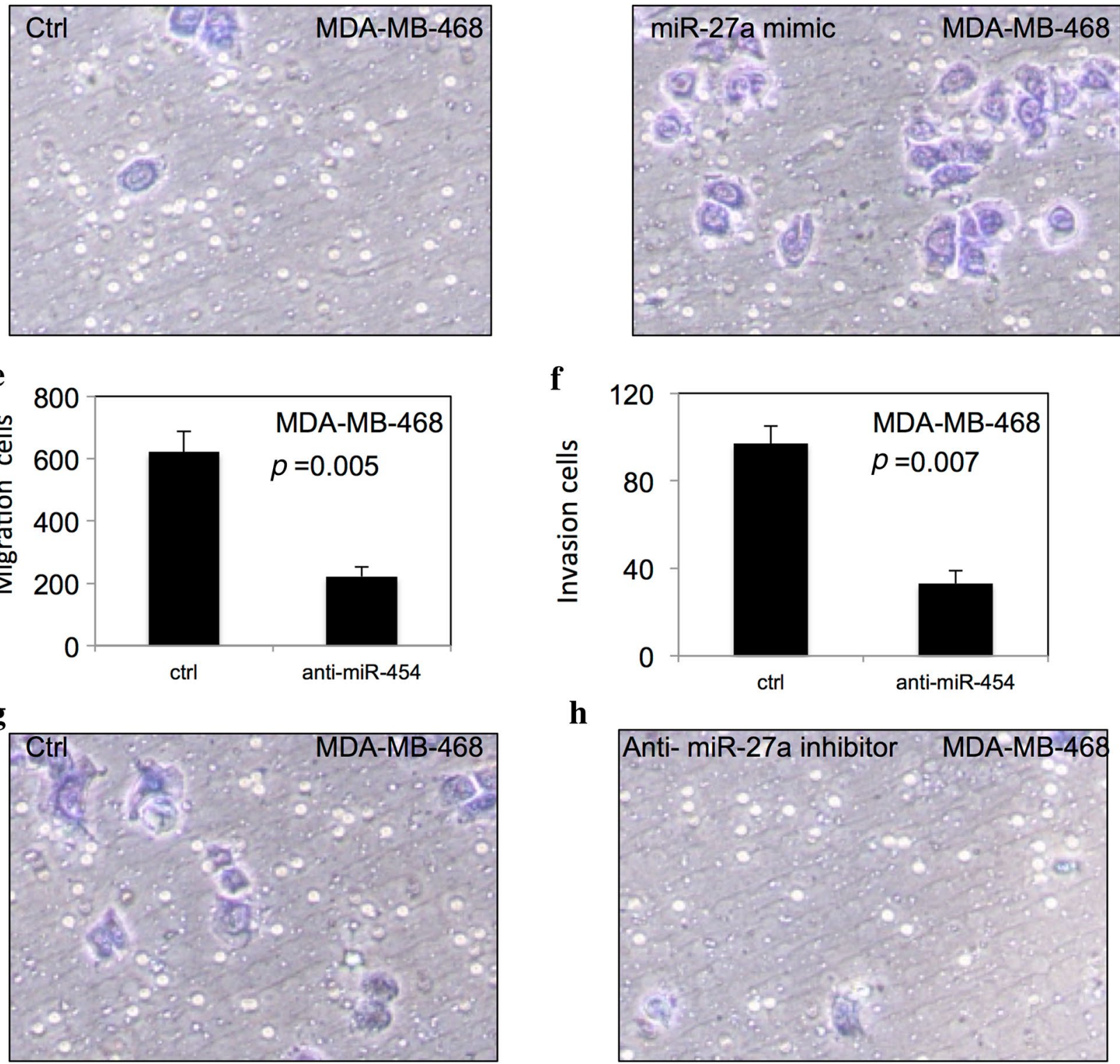

h

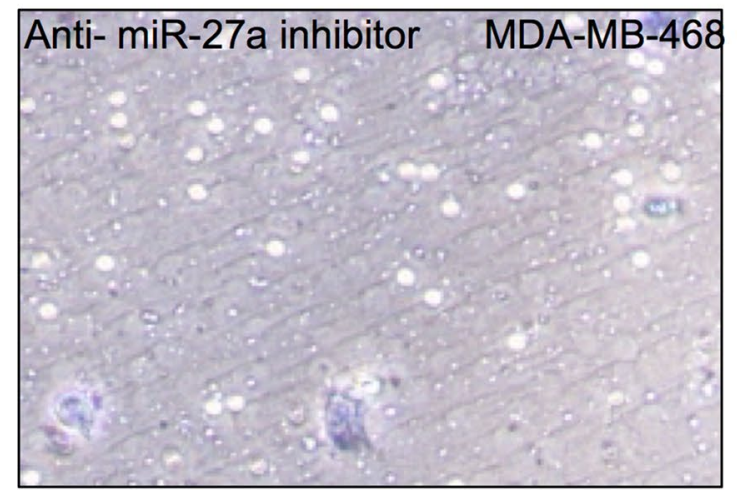

Fig. 5 miR-454 improved migration and invasion of TNBC cells. miR-454 improved migration and invasion in MDA-MB-468 cells (a-h). All experiments were performed in triplicate 


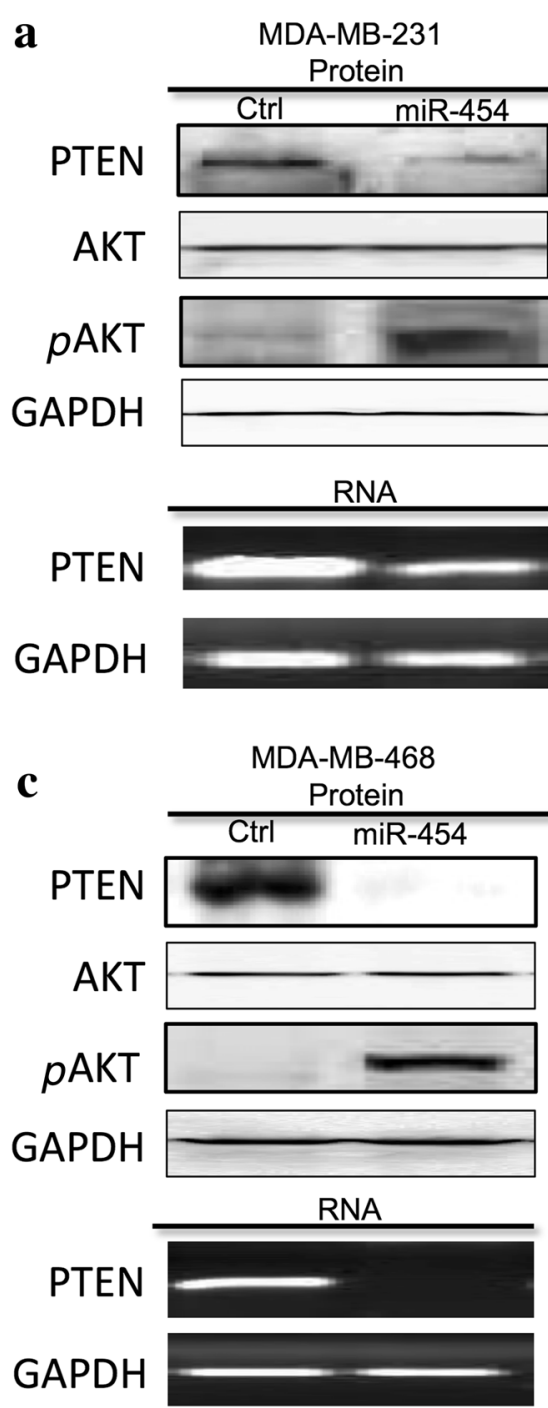

b

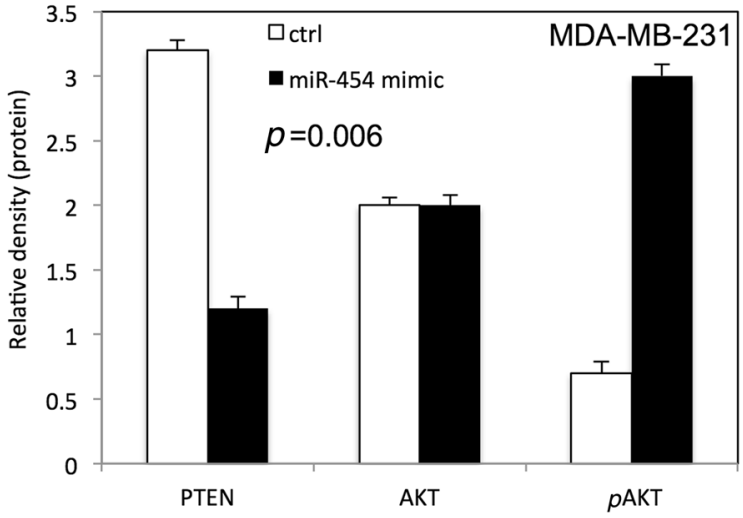

d

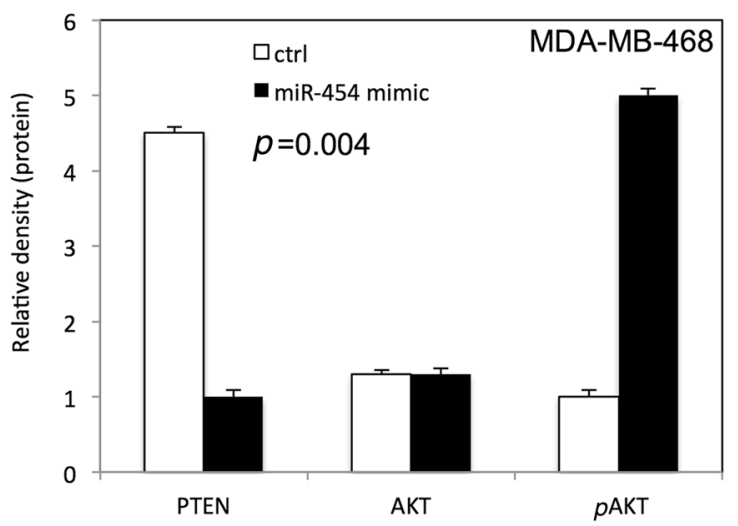

Fig. 6 miR-454 activated pAKT in TNBC cells. a The expression of, pAKT, AKT and PTEN in MDA-MB-231 cells after overexpression of miR-454. b The relative expression level of proteins on MDA-MB-231 cells after overexpression of miR-454 by densitometric analysis. $\mathbf{c}$ The expression of pAKT, AKT and PTEN in MDA-MB-468 cells after overexpression of miR-454. d The relative expression level of proteins on MDA-MB-468 cells after overexpression of miR-454 by densitometric analysis. All experiments were performed in triplicate

\section{Conclusions}

MiR-454 might act as an oncogene to regulate tumorigenesis and malignant progression of TNBC. Our study suggests miR-454 might be used as a potential biomarker to predict the radiotherapy response and prognosis in TNBC.

\section{Authors' contributions}

QL and JL performed the experiments, XM and RP analyzed the results, JL designed the project. All authors read and approved the final manuscript.

\section{Acknowledgements}

Not applicable.

\section{Competing interests}

The authors declare that they have no competing interests.
Availability of data and materials

Yes.

Consent for publication

Yes.

Ethics approval

The study has been reviewed and approved by the Ethics Committee of Jilin University.

\section{Funding}

This project is supported by Young Scientist Award Jilin Province, China (201503102).

\section{Publisher's Note}

Springer Nature remains neutral with regard to jurisdictional claims in published maps and institutional affiliations. 
Received: 5 April 2017 Accepted: 20 July 2017

Published online: 03 August 2017

\section{References}

1. Du XL, Fox EE, Lai D. Competing causes of death for women with breast cancer and change over time from 1975 to 2003. Am J Clin Oncol. 2008;31:105-16.

2. Gebski V, Lagleva M, Keech A, Simes J, Langlands AO. Survival effects of postmastectomy adjuvant radiation therapy using biologically equivalent doses: a clinical perspective. J Natl Cancer Inst. 2006;98:26-38.

3. Tornberg S, Kemetli L, Lynge E, Helene Olsen A, Hofvind S, Wang H, et al. Breast cancer incidence and mortality in the Nordic capitals, 1970-1998. Trends related to mammography screening programmes. Acta Oncol. 2006;45:528-35.

4. Anders C, Carey LA. Understanding and treating triple-negative breast cancer. Oncology. 2008;22:1233-9 (discussion 1239-40, 1243)

5. Lehmann BD, Jovanović B, Chen $X$, Estrada MV, Johnson KN, Shyr Y, et al. Refinement of triple-negative breast cancer molecular subtypes: implications for neoadjuvant chemotherapy selection. PLOS ONE. 2016:11:e0157368.

6. Pogoda K, Niwińska A, Murawska M, Pieńkowski T. Analysis of pattern, time and risk factors influencing recurrence in triple-negative breast cancer patients. Med Oncol. 2013;30:388.

7. Linklater ES, Tovar EA, Essenburg CJ, Turner L, Madaj Z, Winn ME, et al. Targeting MET and EGFR crosstalk signaling in triple-negative breast cancers. Oncotarget. 2016;7:69903-15.

8. Gray MJ, Gong J, Hatch MM, Nguyen V, Hughes CC, Hutchins JT, et al. Phosphatidylserine-targeting antibodies augment the anti-tumorigenic activity of anti-PD-1 therapy by enhancing immune activation and downregulating pro-oncogenic factors induced by $T$-cell checkpoint inhibition in murine triple-negative breast cancers. Breast Cancer Res. 2016;18:50.

9. Krol J, Loedige I, Filipowicz W. The widespread regulation of microRNA biogenesis, function and decay. Nat Rev Genet. 2010;11:597-610.

10. Zhang B, Pan X, Cobb GP, Anderson TA. microRNAs as oncogenes and tumor suppressors. Dev Biol. 2007;302:1-12.

11. Ma L, Teruya-Feldstein J, Weinberg RA. Tumour invasion and metastasis initiated by microRNA-10b in breast cancer. Nature. 2007;449:682-8.

12. Gabriely G, Teplyuk NM, Krichevsky AM. Context effect: microRNA-10b in cancer cell proliferation, spread and death. Autophagy. 2011;7:1384-6.

13. Huang TH, Wu F, Loeb GB, Hsu R, Heidersbach A, Brincat A, et al. Upregulation of miR-21 by HER2/neu signaling promotes cell invasion. J Biol Chem. 2009:284:18515-24.

14. Han M, Wang Y, Liu M, Bi X, Bao J, Zeng N, et al. MiR-21 regulates epithelial-mesenchymal transition phenotype and hypoxia-inducible factor-1a expression in third-sphere forming breast cancer stem cell-like cells. Cancer Sci. 2012;103:1058-64.
15. Zhang CM, Zhao J, Deng HY. MiR-155 promotes proliferation of human breast cancer MCF-7 cells through targeting tumor protein 53-induced nuclear protein 1. J Biomed Sci. 2013;20:79.

16. Ferracin M, Bassi C, Pedriali M, Pagotto S, D'Abundo L, Zagatti B, et al. miR-125b targets erythropoietin and its receptor and their expression correlates with metastatic potential and ERBB2/HER2 expression. Mol Cancer. 2013;12:130.

17. Volinia S, Galasso M, Sana ME, Wise TF, Palatini J, Huebner K, et al. Breast cancer signatures for invasiveness and prognosis defined by deep sequencing of microRNA. Proc Natl Acad Sci USA. 2012;109:3024-9.

18. Sun L, Wang Q, Gao X, Shi D, Mi S, Han Q. MicroRNA-454 functions as an oncogene by regulating PTEN in uveal melanoma. FEBS Lett. 2015;589:2791-6.

19. Liu L, Nie J, Chen L, Dong G, Du X, Wu X, et al. The oncogenic role of microRNA-130a/301a/454 in human colorectal cancer via targeting Smad4 expression. PLoS ONE. 2013;8:e55532.

20. Zhu DY, Li XN, Qi Y, Liu DL, Yang Y, Zhao J, et al. MiR-454 promotes the progression of human non-small cell lung cancer and directly targets PTEN. Biomed Pharmacother. 2016;81:79-85

21. Yu L, Gong X, Sun L, Yao H, Lu B, Zhu L. miR-454 functions as an oncogene by inhibiting CHD5 in hepatocellular carcinoma. Oncotarget. 2015:6:39225-34

22. Liang HL, Hu AP, Li SL, Xie JP, Ma QZ, Liu JY. MiR-454 prompts cell proliferation of human colorectal cancer cells by repressing CYLD expression. Asian Pac J Cancer Prev. 2015;16:2397-402.

23. Cao ZG, Li JJ, Yao L, Huang YN, Liu YR, Hu X, et al. High expression of microRNA-454 is associated with poor prognosis in triple-negative breast cancer. Oncotarget. 2016;7:64900-9.

24. Zhang L, Zhou Z, Mei X, Yang Z, Ma J, Chen X, et al. Intraoperative radiotherapy versus whole-breast external beam radiotherapy in earlystage breast cancer: a systematic review and meta-analysis. Medicine. 2015;94:e1143

25. Abdulkarim BS, Cuartero J, Hanson J, Deschênes J, Lesniak D, Sabri $\mathrm{S}$. Increased risk of locoregional recurrence for women with T1-2N0 triple-negative breast cancer treated with modified radical mastectomy without adjuvant radiation therapy compared with breast-conserving therapy. J Clin Oncol. 2011;29:2852-8.

26. Dent R, Hanna WM, Trudeau M, Rawlinson E, Sun P, Narod SA. Pattern of metastatic spread in triple-negative breast cancer. Breast Cancer Res Treat. 2009:115:423-8.

27. López-Knowles E, O’Toole SA, McNeil CM, Millar EK, Qiu MR, Crea P, et al. PI3K pathway activation in breast cancer is associated with the basal-like phenotype and cancer-specific mortality. Int J Cancer. 2010;126:1121-31.

28. Cully M, You H, Levine AJ, MakTW. Beyond PTEN mutations: the PI3K pathway as an integrator of multiple inputs during tumorigenesis. Nat Rev Cancer. 2006:6:184-92.

\section{Submit your next manuscript to BioMed Central and we will help you at every step:}

- We accept pre-submission inquiries

- Our selector tool helps you to find the most relevant journal

- We provide round the clock customer support

- Convenient online submission

- Thorough peer review

- Inclusion in PubMed and all major indexing services

- Maximum visibility for your research

Submit your manuscript at www.biomedcentral com/submit 